\title{
Innovations as sustainable competitive advantages in the digital economy: substantiation and forecasting
}

\author{
Khuta Gumba ${ }^{1}$, Svetlana Uvarova, ${ }^{2,}$, Svetlana Belyaeva $^{2}$, and Vyacheslav Vlasenko ${ }^{2}$ \\ ${ }^{1}$ Abkhaz State University, University str., 1, Sukhum, Republic of Abkhazia \\ ${ }^{2}$ Voronezh State Technical University, 20-letiya Oktyabrya, 84, 394006, Voronezh, Russia
}

\begin{abstract}
Sustainable development is possible only on the basis of the growth of innovation and the introduction of digitalization in modern conditions. Therefore, it is necessary to speak about the concept of systemic competitiveness, the basis of which is sustainable competitive advantages. This paper is devoted to the problems of forming the competitiveness of construction in the modern economic conditions of the transition to a new technological structure and a digital economy, based on the implementation of sustainable competitive advantages predicted on the basis of foresight and activated by creating "points of innovative growth".
\end{abstract}

\section{Introduction}

Today, the value imperative of the development of the world economy is the formation of a post-industrial economy characterized by the determination of knowledge as a key competence, the formation of an information and communication basis, the networkization of the economy, which determines the role of innovation and digitalization. In these conditions, an essential transformation of competitiveness, the system of its assessment and management methods is necessary.

A stable positive dynamics of competitiveness, characterized not only by maintaining at the current level, but by a stable growth of indicators, can be achieved only with a continuous interconnected updating of the production and technical base, the organizational structure of management, and the economic foundations of functioning based on innovations.

\section{Materials and Methods}

Based on the generalization of scientific sources, the category of competitiveness is characterized by the following features: dynamism (as the ability to change the level of competitiveness over time), comparability (as the ability to measure the level of competitiveness only in comparison with other subjects), polysubjectness (as the dependence on several actors), multifactoriality (as the dependence of the level of competitiveness on a number of factors), multicriteria (as an assessment of the level of competitiveness by a

\footnotetext{
*Corresponding author: uvarova_s.s@mail.ru
} 
number of characteristic criteria), hierarchy (product competitiveness - enterprise competitiveness - industry competitiveness, etc.). In modern conditions, in addition to the listed signs of competitiveness, one should also note the strategic focus (due to the need to implement measures to achieve competitive advantages and the duration of their payback), innovation (based on the dyad "competitiveness-innovation"), adaptability (as a process of constant changes in resonance with environmental changes or ahead of them). The digital economy adds a focus on key competencies to this list, and also emphasizes polysubjectness not so much on the very presence of a number of actors, as on their information and communication interaction within the network organization of these interactions. It is this emphasis that leads to the need to build the concept of systemic competitiveness, since the network interactions of competitive innovation-active subjects of the industry generate a synergistic effect of increasing the level of competitiveness of both the industry itself and the economy as a whole.

\begin{tabular}{|c|c|c|}
\hline THE & $\underbrace{\mathbf{A P I}}_{\mathbf{C O N}}$ & $\begin{array}{c}\text { CRITERIA OF } \\
\text { COMPETITIVENESS }\end{array}$ \\
\hline $\begin{array}{l}\text { - Competition in the market, competition } \\
\text { - The state of the market, characterized } \\
\text { by the structural relationship and the } \\
\text { capabilities of the subjects } \\
\text { A mandatory element of the market } \\
\text { mechanism that ensures the } \\
\text { implementation of the relevant } \\
\text { functions } \\
\text { - Competitiveness of economic entities } \\
\text { that affects the general conditions of } \\
\text { the relevant market }\end{array}$ & $\begin{array}{l}\text { - By comparative } \\
\text { advantage } \\
\text { On the theory of } \\
\text { competition } \\
\text { efficiency } \\
\text { - On the theory of } \\
\text { effective competition } \\
\text { On the theory of } \\
\text { competitive } \\
\text { advantages }\end{array}$ & $\begin{array}{l}\text { - The level of costs and the degree } \\
\text { of differentiation of product } \\
\text { properties } \\
\text { The company's market share, the } \\
\text { level of concentration of } \\
\text { production and capital } \\
\text { - Comparison of economid } \\
\text { performance (price, cost, rate of } \\
\text { return) } \\
\text { - Ownership of certain competitive } \\
\text { advantages }\end{array}$ \\
\hline
\end{tabular}

Fig. 1. Substantiation of competitiveness criteria based on the results of semantic analysis

Accordingly, the basis of systemic competitiveness in the digital economy is the innovative ability of enterprises to adapt to changes in the external environment on a proactive basis through the implementation of the intellectual potential of enterprise personnel within the framework of network information interactions [1]. It should be noted that the lead time lag is determined by the temporal level of competitiveness (strategic or operational). If at the operational level, the priority will be the adaptive nature of changes, then the strategic level requires setting development trends and foresight.

The essence, conditions and trends of the digital economy lead to the need for enterprises, including within the framework of investment projects implemented by them, to search not just for competitive advantages leading to cost reduction, a change in the assortment policy and similar insignificant changes in the products and internal environment of the enterprise, but such competitive advantages that will allow maintaining a competitive position in the future. The transition to a new technological order and the digitalization of the economy leads to the acceleration of the processes of changes, both technological and related organizational and economic ones. Therefore, the use of short-term competitive advantages and investment in appropriate technologies becomes unprofitable and inexpedient. Competitive advantages in the digital economy should be formed on the basis of modern concepts of sustainable competitive advantages, the foundations of which were established by G. Hamel and C.K. Prahalad [2]. According to this concept, industries that have been stable in the recent past change and disappear with the appearance of new products, especially with the advent of digital technologies and corresponding innovative products, as a result of which the competitiveness of enterprises in the future is formed not by today's leadership in existing markets, but by promising leadership in future markets. In this projection, the concept of sustainable competitive advantages is close to the "blue oceans" strategy [3], which presupposes not competition in existing markets by creating and increasing traditional 
competitive advantages, but the creation of future promising markets through the development of innovative products or by analyzing and changing the value curve for existing markets through value innovation.

The development of sustainable competitive advantages allows an enterprise to remain a kind of monopolist in the new market for a certain period of time, before the appearance of imitators and analogues [4]. Digital technologies not only open up wide opportunities for the formation of new markets and the search for innovative products by creating a trend and foresight, but also lead to the need for enterprises to seek sustainable competitive advantages. Accordingly, in the digital economy, the main sources of sustainable competitive advantages are key competencies (including the knowledge resources of the enterprise, educational strategy in the industry, industry rule-making and management that contributes to the development of competencies) and value innovation (in terms of creating innovative products based on foresight). The competitive advantages created on the basis of the listed sources become long-term due to their uniqueness and innovative genesis, as well as highly effective not only from a financial position, but also from the position of industry and social benefits [5]. In the digital economy, the usual competitive advantages, the source of which are resources, will be short-term due to the possibility of imitation.

We believe that planning and development of the unique commercial offer (UCO) of enterprises in modern conditions, characterized by continuous changes based on information and communication flows, digitalization of the economy, the network nature of interaction between participants in the innovation process and a high degree of uncertainty in long-term forecasts, should be based on foresight technologies. Foresight technologies are based on the principles of active modeling of the future, achieving it by joint efforts, on the fundamental role of team decisions in achieving strategic goals and strategic vision of the future object.

The foresight methodology is at the stage of active formation [6]. However, its transdisciplinary nature should be noted. So, on the one hand, foresight can be attributed to the methods of expert assessment and forecasting. On the other hand, proceeding from the immanent formation of the image of the future with a foresight, there is an element of systems engineering. The generality of the applied methodological tools allows tracing the correlation with the project approach to management. Of particular importance, in our opinion, is the interpretation of foresight from the perspective of chaos theory, due to the systemic nature of the technology and the need to implement a systematic approach to the enterprise as an open, nonequilibrium system. The foresight methodology from the perspective of chaos theory is schematically shown in Figure 2. 


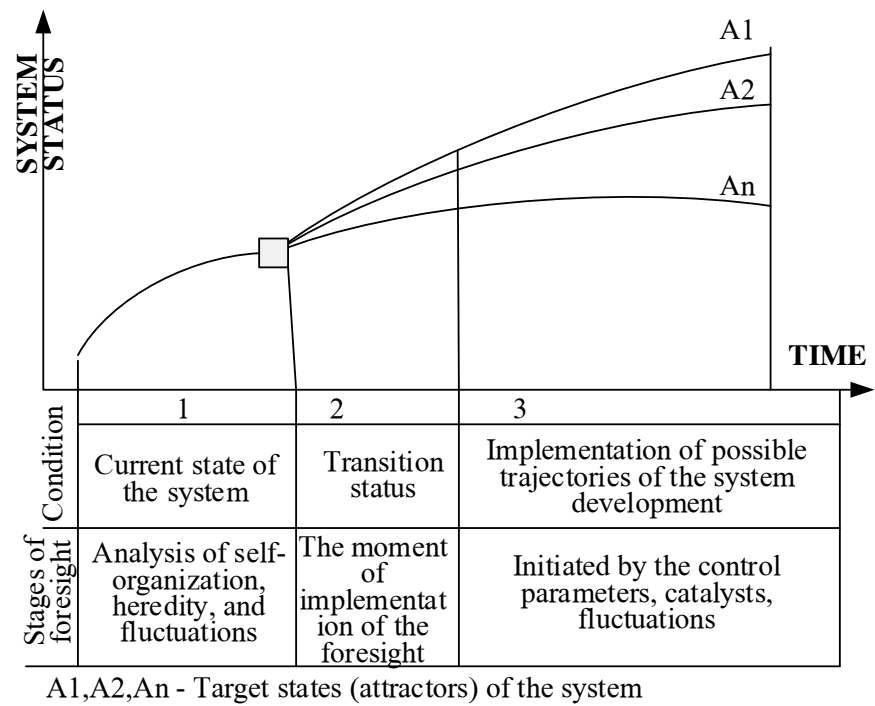

Fig. 2. Substantiation of the use of foresight technology in non-equilibrium systems

From this position, foresight assumes not so much the assessment of the current state as the specificity and heredity of the system under study; identification of many attractors of the system, including target ones; forecasting possible trajectories of the system development towards the selected attractors; development of initiated actions, "catalysts" of system fluctuations. However, it should be noted that it is almost impossible to reliably predict the behavior of the system. Consequently, it is necessary to constantly monitor system fluctuations in order to prevent the transition to an ineffective attractor. It is the approach to the enterprise as to an open non-equilibrium system that makes it possible to effectively use foresight technologies in the development of an innovative strategy and its elements, while preserving the probabilistic nature of the forecast and the activity nature of systems engineering. The latter gives the right to modify the foresight technology from the point of view of the project approach in order to adapt to the solution of applied problems, which should include the problems of modeling "points of innovative growth".

"Points of innovative growth" are, in fact, sustainable competitive advantages at the industry level and in regional projection. Considering the management system of the construction industry and housing and communal services as a subsystem of the country's economic development management system, taking into account the network interactions between industries and the interregional nature of the functioning of industries, the initiation of "points of innovative growth" should be taken as a sustainable competitive advantage due to its strategic focus, innovation and uniqueness. Indeed, each "point of innovative growth" is a unique innovation-territorial object focused on the development of certain technologies, which are subsequently transferred to other industries and regions, thereby forming a synergistic effect and providing industries with systemic competitiveness.

\section{Results}

Nowadays, when the competition between regions for the attracted volume of investments is high, measures are being developed to increase investment attractiveness. Among such measures, it is worth highlighting the creation of PSEDA and the development of industrial parks. We have proved that such an effective government zoning policy promotes diffusion of innovations both in horizontal (within the region) and in vertical (between industries) 
projection by creating "points of innovative growth" in accordance with the "neighborhood effect" of T. Hägerstrand. This thesis is schematically shown in Figure 3.

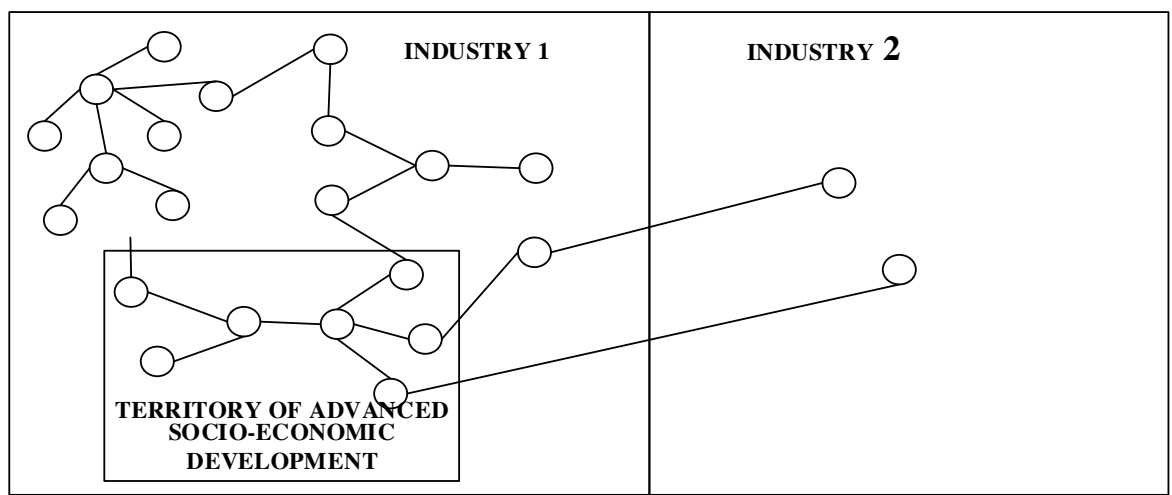

Fig. 3. Networked innovative interaction of enterprises and the effect of "points of innovative growth"

As can be seen from the data in the figure, the UCO of the industry created in the form of "points of innovative growth" are inextricably linked with the innovative activities of enterprises, and the corresponding UCO of enterprises, based on their strategic focus, should be developed within the framework of the enterprise's strategy and its prospective innovation policy.

Consequently, in the formation of a promising innovation policy and the development of an enterprise strategy that allows significantly improving its competitiveness, it is necessary to stimulate innovation processes by introducing modern methods of strategic management of regional zoning and creating "points of innovative growth" that take into account institutional, economic, organizational, information and analytical, and regional aspects of management (Fig. 4).

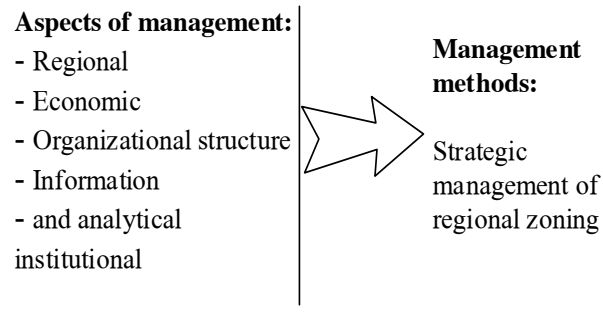

Creation of "points of innovative growth"

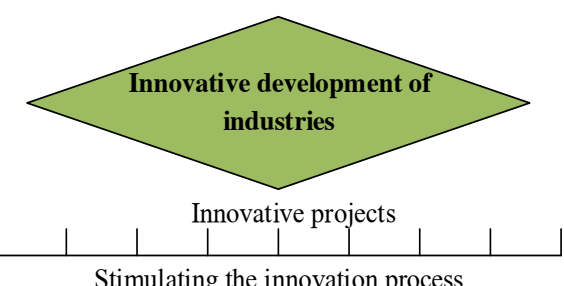

Stimulating the innovation process

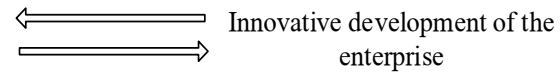

Fig. 4. Schematic diagram of effective management of innovation activities based on the formation of regional "points of innovative growth"

Foresight technologies allow taking into account the multiplicity of stakeholders in the innovative development of enterprises, which is especially important when modeling "points of innovative growth". In general, the algorithm of the foresight technology for identifying the UCO and developing the innovative strategy of the enterprise is shown in Figure 5. 


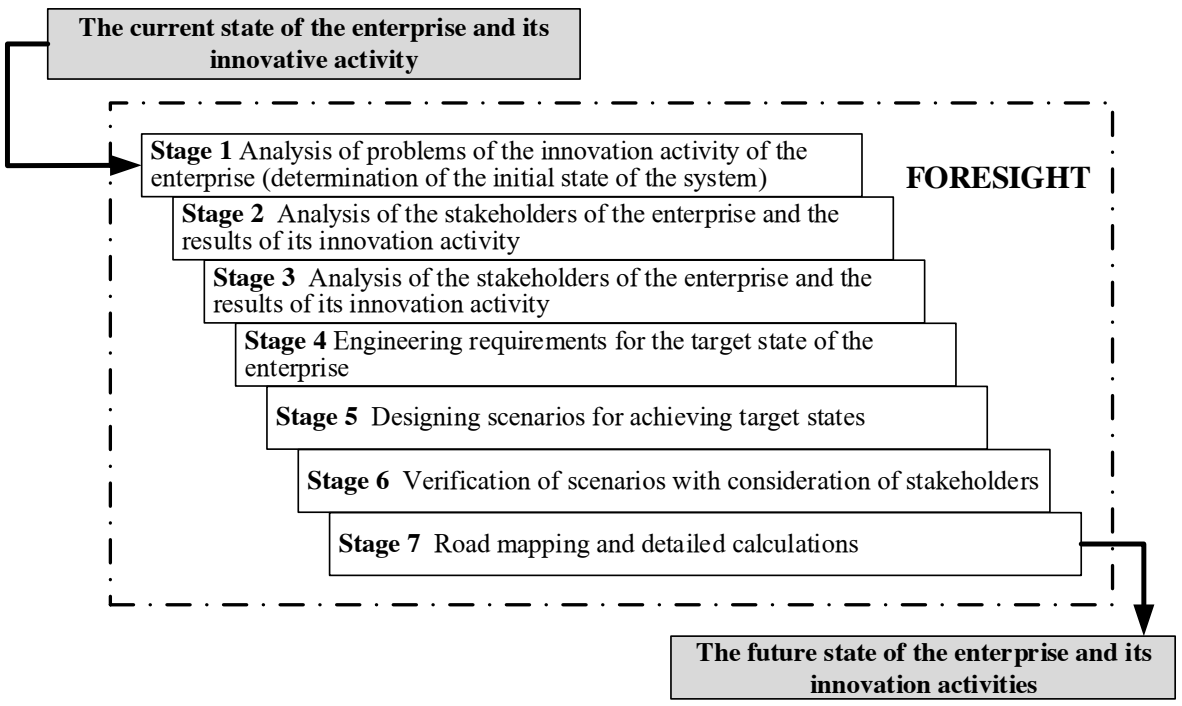

Fig. 5. Algorithm of foresight technology for identifying the UCO and developing an innovative strategy for the enterprise

In general, we consider it expedient to identify the UCO and the corresponding construction of an innovative strategy based on foresight technology. This thesis is based not only on the systematization of the methodological foundations of foresight and the practice of its application in strategic planning, but also on the need, based on the essence of the UCO concept, for system design of the research object (enterprise, industry) in accordance with its target focus and the factor space of the innovative and strategic development. In this context, system design or object transformation are elements of an innovation policy.

The use of the foresight methodology is also substantiated by the network, i.e. communication [7], team nature of the innovation process (Fig. 6). Foresight technologies are based on the principles of active modeling of the future, achieving it by joint efforts, on the fundamental role of team decisions in achieving strategic goals and strategic vision of the future object [8].

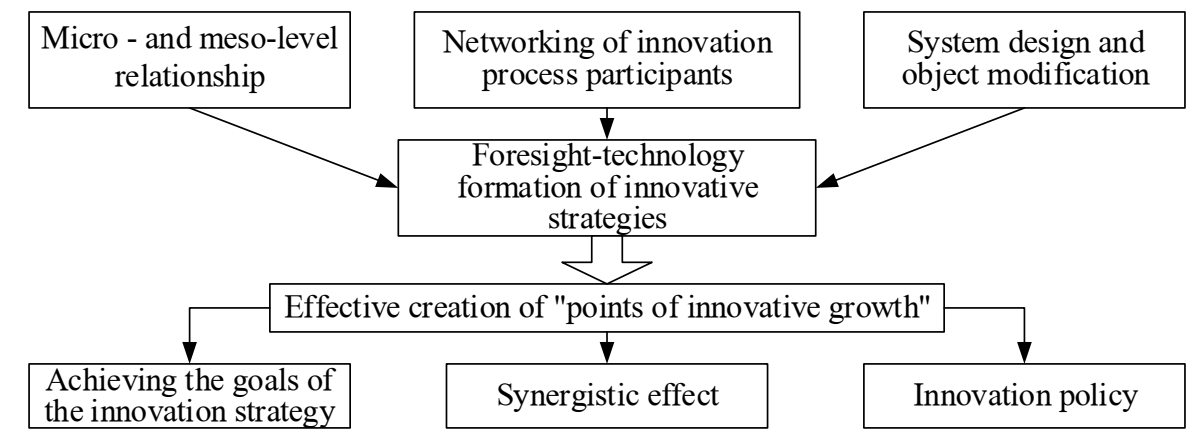

Fig. 6. The scheme of substantiation of the concept of formation of innovative strategies

Foresight can also be implemented in the form of a number of interrelated projects, which will effectively implement the revealed autocorrelation between the systemic competitiveness of the micro- and meso-level of the economy. 


\section{Discussions}

We believe that the application of the foresight methodology to the problem of determining the territorial-sectoral UCO will accelerate the process of diffusion of innovations not only across the country, but also in the sectoral context, which, in turn, will lead to a synergistic effect of systemic competitiveness in the development of innovative activities.

In order to form sustainable competitive advantages of the enterprise and the industry within the framework of the functioning of "points of innovative growth", it is necessary to ensure the effective implementation of innovations within the framework of an investment project, or to assess the feasibility of introducing a UCO as an innovative project, since, ultimately, a UCO is precisely an innovative project due to limited resources, target orientation and a limited number of performers.

In modern conditions characterized as a state of digital transformation of industries and regions, achieving and maintaining a high level of competitiveness is possible only through the implementation of sustainable competitive advantages on an innovative basis, which corresponds to the concept of systemic competitiveness adopted by us. Moreover, enterprises, being elements (subsystems) of the industry management system, in their network interaction on the basis of an information and communication basis regarding the creation and exchange of sustainable competitive advantages, form a synergistic effect of increasing the level of systemic competitiveness of the industry.

\section{Conclusion}

In modern conditions of the knowledge economy, sustainable competitiveness of business entities in construction and housing and communal services can be ensured only with the advanced development of innovations and the activation of innovation activities. It is the innovation activity and performance of economic entities that are imperative for sustainable development of both themselves and the clusters they form, spheres of activity and complexes formed both according to heterarchical and hierarchical principles, as well as territories and regions of activity.

\section{References}

1. S. Belyaeva, O. Belyantseva, N. Safonova, O. Vasilyeva, E3S Web of Conferences, D. Safarik, Y. Tabunschikov and V. Murgul (Eds.), 33, 03021 (2018)

2. G. Hamel, Stockholm School of Economics, 368 (2007)

3. V. Chan Kim, Moscow: Mann, Ivanov and Ferber, 336 (2017)

4. H. M. Gumba, M. I. Mamaev, Scientific journal "Izvestia IGEA", 1 (2014) http: //eizvestia.isea.ru/reader/article.aspx?id=14041 (Last accessed 12.12.2020)

5. A. Kogan, Global Journal of Pure and Applied Mathematics (GJPAM), 12(1), 19-32 (2016)

6. S. A. Tinkov, E. V. Tinkova Indicator to Assess the Level of Development of Productive Capacity and Quality of Life. In: Solovev D. (eds) Smart Technologies and Innovations in Design for Control of Technological Processes and Objects: Economy and Production. FarEastCon 2018. Smart Innovation, Systems and Technologies, Springer, Cham., 139 (2019) https://doi.org/10.1007/978-3-030-18553-4_69

7. K. E. Kovalenko, S. Y. Bakhvalov, , A. O. Zekiy, V. V. Vikulina, S. A. Tinkov, T. V. Tkacheva, Key indicators of innovation activity of Russia (from 2011 to 2017). Journal of Entrepreneurship Education, 22(3), 1-7 (2019) 
8. O. V. Konina, S. A. Tinkov, E. V. Tinkova, Management in Higher Education Based on "Smart Technologies": Digital Managerial Staff vs. Artificial Intelligence. Lecture Notes in Networks and Systems, 155, 1738-1745 (2021) 